\title{
Velvære i wellness-industrien
}

\section{- immaterielt arbejde som materiel praksis}

\author{
Annegrete Juul Nielsen \& Sara Malou Strandvad
}

Oplevelsessamfundet og sundhedssamfundet er to af de betegnelser, der bruges til at beskrive den epoke vi lever i. Varer gøres i stigende omfang til oplevelsesprodukter og befolkningens sundhed gøres til genstand for øget opmærksomhed. Begge diagnoser inkarneres i wellnessindustrien, hvor sundhed udformes som et oplevelsesprodukt. Igennem gen-analyser af en række af etnologen Tom O'Dells observationer fra svenske spa-hoteller diskuterer artiklen produktionen af velværeoplevelser. Sædvanligvis beskrives servicearbejde som immaterielt arbejde eller følelsesarbejde. Med afsæt i et ANT-perspektiv fremhæver artiklen, hvordan materialer gøres aktive for at frembringe følelsen af velvære, og hvordan dette følelsesproduktionsarbejde ikke kun varetages af spamedarbejdere men også af kunderne selv.

Aditionen fra Science and Technology Studies (STS) fokuserer ofte på forholdet mellem teknologier og mennesker. Eksempelvis viser Lucy Suchman i hendes banebrydende bog Plans and Situated Actions: The Problem of Human-machine Communication fra 1987, hvordan interaktionen mellem menneske og computer foregår. Ifølge Suchman formes og omformes menneskelige handlinger igennem brug af computere. Med sit studie demonstrerer Suchman, at relationerne mellem menneske og maskine er afgørende i det nutidige arbejdsliv, og at disse relationer er gensidigt konstituerende, hvilket vil sige, at de ikke kan forklares som resultater af hverken teknologisk eller social determinisme. Det er en pointe, der er blevet formuleret af flere andre forskere, som også trækker på eller arbejder inden for STS-traditionen (fx Grint \& Woolgar 1997; Orlikowski 2005; 2007; Woolgar \& Cooper
1999). I en dansk sammenhæng er den STSinformerede tilgang til teknologistudier i arbejdssammenhænge blevet udfoldet eksempelvis i studier inden for sundhedsvæsenet - af den elektroniske patientjournal (Jensen 2010; Vikkelsø 2005), patientuddannelsesprogrammer (Juul Nielsen 2010) og IT i håndteringen af kroniske patientforløb (Langstrup Nielsen 2005).

I denne artikel vil vi se nærmere på en type arbejde, der adskiller sig væsentligt fra de typer arbejde, som tidligere STS-studier har interesseret sig for. Artiklen drejer sig om det følelsesarbejde som servicearbejdere i wellness-industrien udøver i produktionen af immaterielle goder som velvære og sindsro. Umiddelbart falder arbejde af denne karakter udenfor rammerne af hvad STSperspektivet beskæftiger sig med, fordi der er tale om arbejde karakteriseret ved følelsesbetonede relationer mellem mennesker, og netop ikke relationer mellem mennesker 
og teknologier. Hvor eksempelvis studier af arbejde og organisering i sundhedsvæsenet har tematiseret betydningen af non-humane aktører, har studier af følelsesarbejde traditionelt fokuseret på ansattes håndtering af egne følelser samt deres evne til at fremkalde følelser hos andre (Hochshild 1983). På baggrund af dette fokus har følelsesarbejde været beskrevet som et illustrativt eksempel på immaterielt arbejde, der ikke resulterer i et varigt gode, men producerer et uhåndgribeligt og midlertidigt gode, som for eksempel en følelse af velvære.

Med afsæt i de franske sociologer Gomart og Hennions begreb om forbindelser (attachments) vil vi i denne artikel vise, hvordan det immaterielle arbejde, når det studeres med inspiration fra STS og ANT, snarere end noget luftigt og håndgribeligt bliver til en materiel praksis. Gennem en genanalyse af et studie af svenske spabade, viser vi hvordan wellness-industriens produktion af fx velvære og sindsro sker i en avanceret sociomateriel relation mellem aktive wellness-objekter, wellness-arbejderens følelsesarbejde og wellness-brugerens forberedelser. Det vil sige, det der umiddelbart forekommer immaterielt er i høj grad en praksis, der ikke alene kræver en lang række objekter og materialer, som fx olie, håndklæder og vand, men hvor wellnessbrugerens egen forberedelse og wellnessarbejderens professionelle følelsesarbejde også er afgørende for en vellykket produktion af velvære og sindsro.

Artiklen er bygget op således, at vi starter med at beskrive arbejdslivet for servicearbejderne i wellness-industrien, hvor vi diskuterer den svenske etnolog Tom O'Dells studie af spasteder. Med afsæt i O'Dells studie ser vi nærmere på den kritiske tilgang til arbejdsforholdene for servicearbejdere, og hvordan denne kritik er begrebsliggjort i begreber om det immaterielle arbejde og følelsesarbejde. På denne baggrund argu- menterer vi for behovet for en alternativ tilgang, der med inspiration fra STS og ANT ser nærmere på materialisering af det vi normalt betragter som immaterielt. Inspireret af Hennion og Gomarts forslag om at se hvordan brugere bevidst opsøger at lade sig påvirke af objekter, foreslår vi at se wellnessbehandlinger som teknikker hvor objekter gøres aktive, og hvor fx velvære opstår i forbindelser mellem materialitet, brugspraksisser og wellnessarbejderes følelsesarbejde.

\section{Arbejdslivet i wellness-industrien}

Wellness-industrien dækker et bredt spektrum af behandlinger og serviceydelser rettet mod sundhed, øget velvære, afslapning og kropspleje. Ifølge interesseorganisationen Wellness Tourism Worldwide har wellness tidligere været synonym med spas, dvs. kurbade og skønhedsbehandlinger, men i dag er området vokset til også at indbefatte alternative behandlinger ( $f x$ baseret $i$ new age), sundhedsfremmeaktiviteter (sport, fitness, yoga, meditation, kostprogrammer, detox mv.), medicinsk turisme (plastikkirurgi, tandlægebehandlinger, operationsrejser, rehabiliteringsforløb etc.) samt livsstilsorienterede former for turisme (fx spirituel turisme, øko-turisme, adventure-rejser, gastronomiske rejser). Wellness Tourism Worldwide estimerer at wellness-industrien vokser, fordi der globalt set kan identificeres en øget interesse for sundhed samt en aldrende befolkning og sundhedssystemer der i stigende omfang fragmenteres. Wellness repræsenterer således et voksende marked for forskellige typer oplevelser, der omhandler sundhed og dermed også en voksende arbejdssektor (WTW 2011). I artiklen her vil vi koncentrere os om det klassiske wellness-fænomen: kurbadet eller spastedet, som er den mest brugte betegnelse i dag.

Et af de mest udførlige studier af arbejdslivet i wellness-industrien er udført af den 
svenske etnolog Tom O'Dell og omhandler svenske hotelspas (2010). Igennem deltagerobservationer på spasteder og interviews med medarbejdere på stederne beskriver O'Dell arbejdsforholdene for medarbejderne på spasteder.

De spasteder, som O'Dell undersøger, har et stort antal servicemedarbejdere ansat. Varberg, et af de spasteder O'Dell undersøger, har fx 210-230 medarbejdere ansat hver måned, hvoraf størstedelen er kvinder (2005a, 30). Medarbejderne er overvejende deltidsansatte, ifølge O'Dell fordi arbejdet er for hårdt til at det kan varetages som et fuldtidsarbejde $(2007,112)$. Som en kvindelig ansat i midten af tyverne forklarer:

"Nogle mennesker er så fyldte af negativ energi, som de overfører på dig (...) Jeg er fuldstoendig udmattet når jeg kommer hjem" (O’Dell 2010, 111, vores oversættelse).

Ifølge O’Dell beskriver den unge kvinde, at hun nærmest fungerer som psykolog for klienterne ved at lytte til deres historier og forsøge at gøre dem glade.

Ansættelserne er fleksible, uden faste vagtplaner, og medarbejderne skal ofte stå til rådighed når de ikke er på vagt, særligt i weekender hvor der er travlest. Arbejdet indebærer, at medarbejdernes serviceydelser er af afgørende betydning, men samtidig skal gæsterne ikke lægge mærke til medarbejderne, de skal helst være usynlige og falde i med indretningen. Lønnen er moderat og kan svinge som konsekvens af de forskellige typer deltidsansættelser. O'Dell estimerer dog, at en massør i midten af 00'erne tjente et sted mellem 11.000 og16.500 svenske kroner om måneden (9.200-13.800 danske kroner), mens et spaophold nemt kostede 2.000 svenske kroner for en enkelt dag og 7.790 svenske kroner for fem dage (2005a, 31).

Som kontekst for at forstå arbejdet i wellness-industrien benytter O'Dell begre- bet om 'kulturøkonomi', der beskriver det fænomen, at kultur og økonomi i stigende omfang smeltes sammen (du Gay \& Pryke 2002). O'Dell foreslår i forlængelse heraf at se arbejdet $\mathrm{i}$ wellness-industrien som 'kulturelt arbejde', fordi det består i at "indpakke, iscenesaette og varegøre kultur, affekt og oplevelse" (O'Dell 2010, 11, vores oversættelse). Studierne af arbejdslivet i kulturelle industrier, som O'Dell skriver sig ind i, har en kritisk agenda og $\mathrm{O}^{\prime}$ Dells eget studie indeholder også en kritik af arbejdet inden for wellness-industrien. Som udgangspunkt for studiet af spas nævner O'Dell et ønske om at skrive sig op imod Pine og Gilmores optimistiske lancering af oplevelsesøkonomibegrebet, der i en skandinavisk kontekst er blevet overvejende positivt imødekommet (Pine \& Gilmore 1999; O'Dell 2010, 16).

I den oplevelsesøkonomiske tidsalder eftersøger forbrugerne i stigende omfang oplevelsesprodukter (Pine \& Gilmore 1999). Inden for den oplevelsesøkonomiske litteratur beskrives oplevelser som noget subjektivt og immaterielt, i modsætning til traditionelle materielle produkter (Jantzen $\&$ Rasmussen 2006). Wellness-industriens løfter om sindsro og øget kropsbevidsthed er netop eksempler på immaterielle goder.

Ifølge O'Dell repræsenterer wellness en type oplevelser, der har været overset i litteraturen om oplevelsesøkonomi (2005b, 30). I modsætning til sædvanligvis handlingsmættede oplevelsesprodukter, som for eksempel Disneyland, Las Vegas og Hard Rock Café, sælger wellness-udbydere muligheden for at geare ned i tempo og nyde en stilhed. Fordi hverdagslivet er hektisk, nervepirrende og abrupt har vi netop ikke behov for at opleve dette i vores fritid, og wellness-oplevelser er således ekstraordinære og ikkehverdagslige ved at tilbyde fred og ro. Med andre ord bliver det et generelt fænomen at kurere stress $\mathrm{i}$ arbejdslivet med afbræk i form af wellness-aktiviteter i fritiden. En 
del af O'Dells kritik af arbejdet inden for wellness-industrien er dog netop, at wellness-arbejdet ifølge O'Dell producerer den dårligdom for medarbejderne, som det skal helbrede hos kunderne, nemlig stress:

"ikke kun masseproducenter af øjeblikkelig sindsro, men i medarbejdernes øjne kan de faktisk potentielt forstås som stressproduktionsmaskiner - og på den måde en integreret del af den kulturelle og økonomiske dårligdom de anstrenger sig for at behandle" (2005a, 32, vores oversættelse).

Der er med andre ord ifølge O'Dell et skisma mellem spagæstens positive oplevelse og arbejdets negative konsekvenser for spamedarbejderne, der skal stå til rådighed i weekender, aflaste og oplive negative gæster til en moderat løn og i usikre ansættelser.

Studierne af arbejdslivet i kulturelle industrier, som O'Dell skriver sig ind i, har en kritisk agenda. Michael Hardt og Antonio Negri har foreslået immaterielt arbejde som en samlebetegnelse, der dækker over arbejde, som producerer immaterielle goder såsom services, kulturelle produkter, viden eller kommunikation (Hardt og Negri 2000, 292). Det fremhæves, at det immaterielle arbejde er præget af usikkerhed, freelanceansættelser, ringe eller stærkt svingende indtægter samt vanskeligheder forbundet med at håndtere egne følelser (Hesmondhalgh \& Baker 2008; McRobbie 2002). O'Dell skriver sig ikke ind i diskussionen om det immaterielle arbejde, men hans studie og analyser lægger op til en læsning af wellness-arbejde, som udtryk for produktion af immaterielle goder.

\section{Immaterielt arbejde og følelsesarbejde}

Ifølge den autonome marxistiske kritik af kapitalismen, som Hardt og Negri formulerer, tegner det immaterielle arbejde et over- ordnet billede af arbejdslivet i avancerede kapitalistiske samfund (Hardt 1999; Hardt og Negri 2000). Med begrebet om immaterielt arbejde understreger Hardt og Negri, at der indgår to elementer i det immaterielle arbejde: dels omfatter det service-, følelsesog kreativt arbejde, dels består det i håndtering af information, kommunikation og viden. Analysen af det immaterielle arbejde kritiserer, for det første, at kreativt og intellektuelt arbejde re-tayloriseres og proletariseres (Gill \& Pratt 2008). Igennem denne udvikling bliver ansatte i velbetalte og højstatus-jobs føjet til den voksende gruppe af arbejdstagere med midlertidige, usikre ansættelser - en gruppe der tidligere var forbeholdt personer i lavindkomst- og lavstatusjobs. Denne uhomogene gruppe betegnes det nye precariat, som erstatter det klassiske proletariat på det fleksible arbejdsmarked. Med dette blik for den voksende gruppe af arbejdstagere, som ansættes på usikre vilkår, skriver de autonome marxister sig ind i rækken af samfundstænkere, som har påpeget hvordan usikkerheden øges i det senmoderne arbejdsliv (fx Bauman 2000; Beck 2000; Sennett 1998). Samtidig understreger Hardt og Negri med begrebet om immaterielt arbejde, at arbejde generelt i dag i øget omfang gøres afhængigt af kommunikative og følelsesmæssige kompetencer (Gill \& Pratt 2008). Med andre ord bruges det immaterielle arbejde ikke kun som betegnelse for indholdet af arbejde, men refererer også til måden hvorpå arbejde udføres. Hardt og Negri opererer med begrebet affektivt arbejde (affective labor), som en særlig udgave af det immaterielle arbejde:

"Unlike emotions, which are mental phenomena, affects refer equally to body and mind. In fact, affects, such as joy and sadness, reveal the present state of life in the entire organism, expressing a certain state of the body along with a certain mode of thinking. Af- 
fective labor, then, is labor that produces or manipulates affects.... One can recognize affective labor, for example, in the work of legal assistants, flight attendants, and fast food workers (service with a smile). One indication of the rising importance of affective labor, at least in the dominant countries, is the tendency for employers to highlight education, attitude, character, and "prosocial" behavior as the primary skills employees need. A worker with a good attitude and social skills is another way of saying a worker is adept at affective labor" (Hardt \& Negri 2004, 108).

Hardt og Negri bruger dog fortrinsvis begrebet om affektivt arbejde diagnostisk i forhold til deres karakteristik af det immaterielle arbejde og arbejdsforholdene i det de kalder det senmoderne arbejdsliv. I relation til wellness-industrien er spa-arbejderne $\mathrm{fx}$ ansat $\mathrm{i}$ lavbetalte, midlertidige, lavstatus-jobs, som er underlagt vilkår angående følelseshåndtering, der kan være personligt omkostningsfyldte (O'Dell 2005a). Hardt og Negris begreb om affektivt arbejde siger dog ikke så meget om præcis hvilke handlinger, interaktioner og processer der indgår i affektivt arbejde, hvilket netop er det, som vi er interesseret $\mathrm{i}$ at se nærmere på i denne artikel.

Et mere analytisk anvendeligt begreb $\mathrm{i}$ denne sammenhæng (der også trækker på marxistisk teori), finder vi hos den amerikanske sociolog Arlie Hochschild, der har formuleret et lignende begreb, nemlig følelsesarbejde (emotion work). Hochschild, der er rundet af pragmatisk amerikansk sociologi, begrebsliggør følelsesarbejde som en måde at beskrive og forstå de typer af arbejde, hvor der er ansigt-til-ansigt interaktion. Hochschild definerer følelsesarbejde, som det arbejde med at tilbageholde eller fremkalde følelser, der kræves for at opretholde en ydre fremtoning. En ydre fremtoning, der uagtet om der er i overensstemmelse med personens indre følelser, kan afføde den rette stemning eller humør hos modtageren (Hochschild 1983). Fx argumenterer Hochschild for, at når stewardessen smilende yder den besværlige flypassager en venlig, hjælpsom og kompetent service, så udfører hun en del af det følelsesarbejde hun er trænet i at levere, for at den besværlige flypassager også vælger at flyve med stewardessens arbejdsgiver næste gang. For stewardessen indebærer følelsesarbejdet, at hun skal kontrollere, hvad hun siger til flypassageren, men hun skal også sørge for, at hendes ansigtsudtryk, kropsholdning og 'følte' følelser signalerer den venlighed, hjælpsomhed og kompetence, hun forventes at levere (ibid). Med følelsesarbejde begrebsliggør Hochschild således, hvordan følelser indgår som nødvendige elementer i det immaterielle arbejde.

Som Astrid Jespersen (2007), i et studie af danske lægers engagement i konsultationsprocesser, påpeger, så har Hochschilds begreb om følelsesarbejde imidlertid den svaghed, at det kredser om følelser som intersubjektive, hvilket blandt andet ses ved, at Hochschild opererer med en analytisk skelnen mellem fysisk, mentalt og følelsesarbejde (Jespersen 2007, 100). Det indebærer, at Hochschilds begreb om følelsesarbejde udelukker en, i vores (STS) optik, væsentlig pointe, nemlig, at arbejdsprocesser altid er heterogene og sociomaterielle. I vores optik produceres følelser ikke alene mellem mennesker eller som i tilfældet med følelsesarbejde af servicearbejderen og med kunden som (passiv) modtager. Fra alene at have fokuseret på wellness-arbejderen, sætter vi derfor nu i højere grad fokus på, hvordan også non-humane aktører og wellness-brugeren indgår i produktionen af immaterielle goder som velvære og harmoni.

\section{Produktion af wellness}

I forlængelse af Jespersens kritik vil vi derfor tilføje, at begrebet om følelsesarbejde 
ikke inddrager, at produktionen af fx velvære, balance eller harmoni i wellnessindustrien ikke alene sker efter en særligt scriptet relation mellem wellness-bruger og wellness-arbejder, men også i relation til hvad der med et typisk STS-begreb benævnes non-humane aktører. I wellness sammenhænge er det fx det iskolde vand, den dæmpede belysning, røgelsen, de varme sten, de bløde frottébadekåber osv.

I sine analyser af svenske spas fremhæver O'Dell, at spasteder bygger på fysiske og materielle praksisser:

"De produkter som de knokler for at tilbyde (sindsro, harmoni, balance og så videre) er højest flygtige, men det som spas rent faktisk gør, er meget konkret og fysisk" (2010, 20, vores oversættelse).

Med henvisning til begrebet om materiel kultur argumenterer O'Dell for at "spas er designede til og tilstroeber at vaere affektive" (ibid.). På denne måde åbner O'Dell op for at se på, hvordan materialer bruges til at skabe følelsesmæssige påvirkninger, og hvordan brugen af materialer såsom tekstiler kan opløse dikotomien mellem subjekt og objekt (Attfield i O’Dell 2010, 71), men det er ikke et tema, han udfolder.

I stedet argumenterer O'Dell for, at produktionen af wellness primært omhandler tre temaer: goestfrihed, magi og produktionen af følelser (2010). Temaet om gæstfrihed tager afsæt i, at dette fænomen egentligt angår privatsfæren; at blive inviteret indenfor i private hjem. Det er samtidig en udbredt term inden for serviceindustrien. O'Dell diskuterer på denne baggrund, og med inspiration fra Derrida, hvorvidt og hvordan det er muligt for professionelle servicearbejdere i en kommercialiseret situation at yde en imødekommende service, som imiterer den private og oprigtige gæstfrihed (2007).
Det andet tema, magi, handler om den "noermest mystiske" tone, der bruges til at sælge og formidle spaoplevelser (2005a, 19 , vores oversættelse). Ifølge O’Dell indgår der i spabehandlinger elementer af new age filosofi, som trækker på forestillingen om magisk helbredelse. Med afsæt i Mauss' tilgang til magi, som er baseret på en vilje til at tro, der er kollektivt betinget, foreslår O'Dell at se spas som steder, hvor der foregår magiske ritualer (ibid.).

Endelig angår det tredje tema de følelser, som produceres på spasteder. O'Dell fremhæver, at oplevelserne af velvære, sindsro og luksus skabes gennem manipulation af kroppen og sanserne. Til at forklare hvordan dette foregår, inddrager O'Dell begrebet om materiel kultur (Miller 1998), og argumenterer for, at der indgår en række materialer i produktionen af følelser på spasteder, for eksempel mudder, tang og olier, men frem for alt vand (i form af varme bade, kolde bade, dampbade, boblebade, saltvandsbade og drikkevand) (2005a, 24; jf. 2010, 20; 2007, 111).

Ved at lade det materielle aspekt forblive i baggrunden mener vi, at O'Dell indirekte kommer til at afskrive spabehandlingers effekter som indbildte, baseret på overbevisning, og som ikke havende reelle konsekvenser. O'Dell kobler dette til den udbredte brug af new age i behandlingerne og argumenterer dermed for, at de alternative behandlingsformer, der trækkes på, er dubiøse - for eksempel når behandlingen handler om, at man skal lade sit indre selv træde frem (Heelas i O'Dell 2010, 78).

I næste afsnit følger vi op på kritikken af følelsesarbejdet som ikke alene intersubjektivt, og præsenterer en ANT-inspireret tilgang til, hvordan vi kan forstå betydningen af wellness-objekterne og wellness-brugerens egne forberedelser som væsentlige for det immaterielle arbejde. 


\section{Materialer og brugeres forberedelser}

Inden for ANT-traditionen har Emilie Gomart og Antoine Hennion i studier af stofmisbrugere og musikelskere vist hvordan forbindelser til objekter skabes som udtryk for, hvad de kalder aktiv passion (1999):

"Drugs, like music (or love, or wine tasting...) throw the user neither into social construction and 'pure' ritual nor into chemistry or aesthetics (the mechanical effects of drugs or musical pieces themselves). Skilled gestures and techniques of the body, appropriate dispositions of the mind, obsessive tidiness in installation, organizational control of time and space, quasi-scientific expertise of the objects involved and adeptness in managing their passion as a collective construction of a 'connoisseur's' practice ...these practical and social modalities are necessary but do not work by themselves. Our descriptions, observations, and interviews constantly reveal a subtle interweaving between being abandoned to an external power and the virtuosity of practices, of manual, and of social skills. The user passes between active and passive. That is, between 'I am manipulated' (because I agree to it) and 'I manipulate' (an object which is stronger than myself)" (Gomart \& Hennion 1999, 243)

Forbindelsen til objekter består ifølge Gomart og Hennion i en udøvelse af ønsket om at blive påvirket af objekterne. Med andre ord bruges stoffer og musik for at få dem til at overvælde brugeren. I studier af musikelskere demonstrerer Hennion, hvordan brugen af musik er en blanding af at være aktiv og passiv:

"It is an active way of putting oneself in such a state that something may happen to oneself" $(2007,109)$.
Musikelskeren søger aktivt at blive passiv og lade musikken udøve en påvirkning. Med andre ord bringes objekter i spil for, at de kan få indflydelse og blive aktive, og Hennion foreslår på den baggrund, at både brugeren og objektet konstitueres gennem brugspraksisser (2001). Tilsvarende illustrerer Gomart, at stofmisbrugere ikke kun er slaver af deres afhængighed, men også forbereder sig på at blive 'determineret' (2004, 100). Ifølge Gomart virker stoffer ikke autonomt, men bliver virksomme under særlige forhold. Stofferne tilbyder sig som muligheder, det er op til misbrugeren at gribe. Et centralt element $i$ argumentet om at musik og stoffer bruges for at disse objekter skal blive aktive og udøve en indflydelse på brugerne, består i brugspraksisserne. Brugeren er i Gomart og Hennions optik ikke uforberedt eller ukyndig. Tværtimod er der tale om connaisseurs. Både musikelskeren og stofmisbrugeren har en grundig viden om de objekter, som de bruger, og de har nogle særdeles veludviklede praksisser omkring at bruge objekterne og få dem til at blive aktive. Med andre ord kræver det øvelse, forberedelse og forfinelse at få et objekt til at udøve en påvirkning. Ifølge Gomart og Hennion er der således tale om en gensidig forandrende relation mellem udøveren og objektet:

"Indeed, there is slow interpenetration and reciprocal enabling between procedures, skills and properties of the object on the one hand, and the ever finer capacity of the amateur to perceive them on the other. (...) Only to an expert user is there 'pure' heroin or 'pure' Bach. In competent use, the propensity of drugs and music unfolds. Expertise is not achieved, then, in spite of, or alongside, the materiality of the object" (Gomart og Hennion, 1999, 238).

Latour fremhæver samme pointe med henvisning til træningen af parfumenæser 
(2004). Frem for at se kroppen og de objekter den møder, som to adskilte og på forhånd definerede størrelser, argumenterer Latour for at begge dele opstår i mødet med hinanden. Kroppen er således et 'interface' med et repertoire af praksisser, der udvikles til at lade sig påvirke:

"to have a body is to learn to be affected, meaning 'effectuated', moved, put into motion by other entities, human or non-humans" (ibid., 205, originalens fremhævning).

Efterhånden som kroppen trænes og lærer at blive påvirket kan den i større og større omfang beskrives. Tilsvarende med de objekter, kroppen møder. I stedet for at se objekter som nogle der har henholdsvis 'primære kvaliteter', som kan måles videnskabeligt, og 'sekundære kvaliteter' der opstår i individuelle brugspraksisser, foreslår Latour at objekter kun kan begribes gennem de praksisser hvori de indgår.

I det følgende vil vi med afsæt i Gomart, Hennion og Latours argument om at ophæve opdelingen mellem subjekt og objekt, illustrere konturerne af en ANT-inspireret analyse af det immaterielle arbejde via en genanalyse af O'Dells studier af svenske spas. I analysen vil vi vise hvordan det immaterielle arbejde, når det studeres i denne optik, bliver til et fænomen med reelle konsekvenser og hvordan produktionen af fx velvære eller balance sker i en avanceret sociomateriel relation mellem aktive wellness-objekter, wellness-arbejderens professionelle følelsesarbejde og wellness-brugerens forfinede forberedelser.

\section{Wellness som materiel praksis}

Som vi vil vise i det følgende er spastedernes impulsfri indretning og spaarbejdernes følelsesarbejde i form af dæmpede stemmer og langsomme bevægelser væsentlige men ikke fyldestgørende elementer i produktionen af velvære. Spagæstens egne forberedelser er lige så vigtige.

To af de spas, som O'Dell går særlig i dybden med, er Varberg og Hasseludden. Varberg er et gammelt sanatorium fra starten af 1800-tallet syd for Göteborg, som i 1990 'erne er blevet bygget om til et konference- og spahotel, der i sin præsentation trækker på sin historie som et sted med klassiske og medicinske behandlinger. Den anden case er Hasseludden, bygget i 1970'erne i omegnen af Stockholm af den svenske arbejderbevægelse som konferenceog uddannelsesinstitution, og i 1990'erne ombygget til spa efter det japanske koncept kaldet Yasuragi. Trods deres forskelligheder er begge steder indrettet så de, ifølge en manager på Varberg, giver gæsten en "følelse af sindsro" (O'Dell 2007, 110, vores oversættelse). O'Dell beskriver, hvordan stemmer dæmpes og bevægelser nedtones, allerede når man træder ind på Varberg. På Hasseludden bliver gæsten fra start iklædt en kimono-lignende, yukata badekåbe og badetøfler, så bevægelsesfriheden nedsættes. Manageren på Varberg fortæller:

"Det er ret sjovt. Mange af de nye gaester, der kommer her, siger, at de oplever at en følelse af sindsro skyller ind over dem, når de kommer ind i lobbyen. Og det er hvad mange mennesker $i$ dag loenges efter - at falde til ro og slappe af" (O'Dell 2005a, 22, vores oversættelse).

Tilsvarende fortæller en tidligere manager fra Hasseludden om stedet i en coffee-tablebog:

"Ideen er at vores goester lukker den ydre verden ude og basalt set ikke laver noget. Det er $i$ den slags øjeblikke hvor man får vejret, hvilket vi har brug for $i$ vores liv. Det er i de øjeblikke, at man samler styrke, får fornyet energi, har 
tid til refleksion og måske loerer at toenke indefra og ud" (ibid., 23, vores oversættelse).

Med andre ord er spastederne indrettet til at trække tempoet ud af det almindelige travle hverdagsliv og flytte fokus fra udefrakommende påvirkninger til indre ro (2005b, 30). O'Dells egne oplevelser med spas kan bruges til at illustrere konturerne af en STSinspireret analyse.

I en af de tidligste beskrivelser af en spaoplevelse fortæller O'Dell:

"På Varberg er den største specialitet 'tangbadet', hvor kroppe nedsoenkes i soerlige troetønder og derefter skrubbes med tang af en medhjoelper, som kontrollerer vandtemperaturen for at sikre at det hverken er for koldt eller varmt. Efter tangskrubningen efterlades badegoesten alene for at flyde $i$ vandet og lytte til beroligende musik. Blandt indviede badegoester er der en forståelse af at dette regnes for at voere et afslappende øjeblik.

For spa-novicen kan hele ritualet dog nemt blive vaevet ind i bekymringer om seksualitet eller selvbevidsthed angående hvordan din krop fremtroeder i øjnene på de fremmede, der er ansat til at pleje dig (...) spørgsmål kan ødeloegge øjeblikket: 'Bør jeg tage mine shorts af? Bør jeg tale til damen som skrubber mig? Kommer hun tilbage og tager mig ud af det her badekar eller skal jeg rejse mig når musikken begynder at kede mig? Hvorfor tabte jeg ikke et par kilo inden jeg kom herhen?' På den måde kan øjeblikkets magi voere usoedvanligt skrøbeligt" (2005a, 24f, vores oversættelse).

Som det fremgår af O'Dells beretning betyder hans manglende kendskab til spaoplevelsen, at han har svært ved at overgive sig til behandlingen. Det er altså ikke, som O'Dell beskriver, alene et spørgsmål om, at følelsesarbejderen er god til at konstruere en gæstfri, omend kunstig hjemlig, situation.
Gæstens egen tilgang er også afgørende for produktionen af oplevelsen. Som O'Dells beretning vidner om, så er det umuligt at opnå den fuldendte spaoplevelse, når man mest er optaget af, at alt er fremmed og uvant. Med andre ord får novicen ikke det samme ud af oplevelsen, som en spagæst med en mere veløvet tilgang. O'Dell beskriver da også hans egne oplevelser i en mere munter tone nogle år senere, hvor han har lært at gå i spa og er blevet velbekendt med wellness-verdenen. I forordet til hans bog om spasteder takker han sin kone:

\begin{abstract}
"Mens de fleste par på de spasteder, som vi besøgte, hyggede og brugte deres ophold som en tid til at voere sammen 'bare os to', måtte du traekkes med en mand som for rundt og tog billeder og notater. Det var en opførsel som til sammenligning noesten kunne få hverdagen til at virke soerdeles romantisk. Jeg lover, at hvis vi nogensinde besøger et spasted igen, så vil notesbogen blive efterladt derhjemme" (2010, 8, vores oversættelse).
\end{abstract}

$\mathrm{Nu}$ fremstår 'ritualet' ikke længere mystisk og ubekvemt - spaoplevelsen beskrives (indirekte) som nydelsesfuld og forstyrrelser som ødelæggende for hengivelsen til oplevelsen. Med andre ord går O'Dell ikke længere uforberedt i spa. Tværtimod har han måske ligefrem en veludviklet praksis omkring at gøre spaoplevelsen effektfuld og dermed opnå den sindsro og kropslige afslapning, som er formålet. På den måde peger O'Dells egen udvikling som spagæst på Gomart, Hennion og Latours tese om, at kroppen skal lære at blive påvirket, og at vi aktivt søger at få objekter til at udøve en indflydelse på os. Eksemplet med O'Dells opøvelse af spakompetencer illustrerer, at gæsten ikke manipuleres, men aktivt indgår i at blive manipuleret - som novice på en ubehjælpsom måde, hvorved resultatet bliver relativt virkningsløst, og som kender 
på en kyndig facon, der gør at spaoplevelsen kan udfolde sig mere virkningsfuldt.

På baggrund heraf vil vi foreslå, at produktionen af velvære også er afhængig af, at spagæsten udvikler teknikker til at gøre behandlingerne effektfulde, altså fx træner kroppen til at lade sig påvirke og influere af materialer, som derigennem bliver aktive. Imidlertid er en sådan co-konstruktion af subjekt og objekt ikke det resultat som O'Dell kommer frem til, selvom vi mener hans empiriske eksempler peger i den retning. Tværtimod vender O'Dell tilbage til at forklare spaoplevelsen som et magisk ritual, hvor gæsten udsættes for en udefrakommende påvirkning. Denne forklaring fremgår eksempelvis af $\mathrm{O}^{\prime}$ Dells skildring af flydetanken.

Flydetanken er den spabehandling, som O'Dell beskriver mest udførligt: Et lavtvandsbassin med så høj saltkoncentration at kroppen flyder ovenpå vandet, hvor en enkelt gæst lukkes inde under et låg og $\mathrm{i}$ totalt mørke oplever vægtløshed i $45 \mathrm{mi}$ nutter (ibid., 76f). En spamanager opfordrer O'Dell til at prøve behandlingen:

"Du bliver nødt til at gøre det. Det gør du virkelig! For det der sker, når du ligger i tanken og virkelig lader din krop tage over (...) du slapper af. Og hvis du falder i søvn, kommer du noermest ind $i$ så dyb en søvn, at du føler det som om, du har hvilet. Du har ikke kun hvilet dine muskler og din krop men også din hjerne" (ibid., 79, vores oversættelse).

Entusiastisk på O'Dells vegne booker spamanageren en gratis session til ham i tanken. O'Dell beskriver, hvordan han på det aftalte tidspunkt føres ind i et lille omklædningsrum oplyst af stearinlys. Her får han besked på at klæde sig af og lægge sig nøgen i tanken for at få den fulde oplevelse af vægtløshed. Desuden instrueres O'Dell i, hvad han betegner som en række rutiner og procedurer. For det første at smøre vaseline over alle sår og hudafskrabninger, fordi saltvandet ellers vil svie. For det andet at tænde lyset i tanken før den entreres, lukke låget, lægge en oppustelig pude bag nakken og slukke lyset. For det tredje at tage et varmt bad efter behandlingen for at skylle saltet af, vaske kroppen med en særlig sæbe og tørre den med et stort blødt håndklæde. Endelig, efter at have taget tøj på, at blive ført ind i et loungeområde foran en pejs hvor der serveres en frugtbuffet og den afsluttende instruks lyder: "Saet dig nu ned og slap bare af et stykke tid her" (ibid., 81, vores oversættelse).

O'Dell beskriver behandlingen i flydetanken som et ritual, hvor gæsten skridt for skridt, igennem de forskellige rutiner og procedurer, føres væk fra den profane verden og ind i tankens fuldkomne stilhed og tilbage igen. Der skabes på den måde en transformationsproces, hvor gæsterne "ritualistisk føres til afslapning og velvoere" (ibid., 82). Ifølge O’Dell påvirkes gæsterne af de forskellige sansestimuleringer uden at de altid er klar over, hvad der foregår (ibid., 105). På den måde bliver forklaringen på spabehandlingernes effekt igen ført tilbage til deres magiske komponenter:

"I de tilfoelde hvor goesten forlader spastedet og foler, at vedkommende har det bedre, vil jeg argumentere for at magien har virket" (ibid., 90).

Som alternativ til O'Dells forklaring vil vi foreslå, at de materielle rutiner og procedurer, som han identificerer, netop skaber oplevelsen - de skaber ikke rum for at 'magi' kan virke og oplevelsen derigennem kan opstå. I vores optik er det altså ikke behandlingernes 'magiske' komponenter, der får dem til at blive virkningsfulde, men derimod selve de materielle rutiner, hvormed de praktiseres. I tilfældet med flydetanken vil det eksempelvis sige alle wellness-objekterne, som 
fx vaselinen, saltvandsbassinet, mørket, vægtløshed osv.; wellness-arbejderens professionelle følelsesarbejde i form af en kyndig, rolig og venlig guidning gennem forløbet fra afklædning til frugtbuffet; samt ikke mindst spagæstens egne forberedelser til, at følelsen af at være en vægtløs krop afsondret fra verden forbindes med velvære og sindsro (og ikke klaustrofobi og panikangst).

I stedet for at karakterisere spaoplevelsen med ritualbegrebet, vil vi opfordre til at fastholde fokus på de rutiner og procedurer, som O'Dell illustrativt demonstrerer, hvordan han lærer efterhånden. Som betegnelse for de teknikker, der skal tillæres for at kunne gå i spa, vil vi foreslå at anvende de klassiske ANT-begreber om handleprogrammer (Latour 1991) og manuskripter (Akrich 1992), der understreger, at teknologier foreskriver bestemte handlemuligheder. Gennem at anskue spabehandlinger som sociale teknologier kan behandlingerne omtales som programmer, der har indskrevet bestemte praksisser, gæsterne skal afkode og følge eller lave antiprogrammer imod. I tillæg hertil kan spamedarbejderne beskrives som forvaltere af objekter og materialer. Dermed drejes fokus i retning af det konkrete arbejde, de udfører, fremfor karakteristikkerne af servicearbejderne som magikere (O'Dell 2005a), der indikerer, at arbejdet består i at skabe en illusion. Vi vil som alternativ hertil argumentere for at det følelsesarbejde, som spamedarbejderne udfører, er bundet op på de materialer, som anvendes til at skabe spaoplevelserne. Det vil med andre ord sige, at følelsesarbejdet ikke blot foregår i ansigts-til-ansigts-relationer, men medieres gennem de objekter, der bringes til at udøve en indflydelse på gæsten. På den måde baseres det immaterielle arbejde på materialer, og spamedarbejderens funktion bliver at bestyre flydetanke, frottéhåndklæder, massageolier mv.

\section{Konklusion}

I artiklen her har vi taget STS og ANT med på arbejde i wellness-industrien, hvor det, der produceres, ofte beskrives som luftigt, uhåndgribeligt og uden reelle konsekvenser. Med afsæt i Gomart og Hennions begreb om forbindelser og Hochschilds begreb om følelsesarbejde har vi argumenteret for, at det immaterielle arbejde materialiseres, når det analyseres med inspiration fra ANT. Dernæst har vi med Tom O'Dells studie af svenske spasteder som eksempel illustreret, hvordan velvære i wellness-industrien opstår i en sociomateriel relation mellem wellness-objekter, wellness-arbejderens professionelle følelsesarbejde og wellness-brugerens forfinede forberedelser.

Det immaterielle arbejde, fx i serviceindustrien og omsorgssektoren, har længe oversteget det, vi traditionelt forbinder med materielt arbejde, det vil sige produktionen af varer og produkter. Med denne artikel har vi peget på, at arbejdslivsstudier af det immaterielle arbejde med fordel kan studere dette som en heterogen og sociomateriel praksis, hvor det ikke kun er servicearbejderens (følelses)arbejde der har betydning, men også kundens.

\section{Referencer}

Akrich, Madeleine (1992): The De-Scription of Technical Objects, i Wiebe E. Bijker \& John Law (red.): Shaping Technology/Building Society: Studies in Sociotechnical Change,
Cambridge: MIT Press, 205-224.

Bauman, Zygmunt (2000): Liquid Modernity,

Cambridge, Polity Press.

Beck, Ulrich (2000): The Brave New World of 
Work, Cambridge, Polity Press.

Crang, Philip (1997): Performing the Tourist Object, i John Urry \& Chris Rojek (red.):

Touring Cultures: Transformations of Travel and Theory, London, Routledge, 137-154.

du Gay, Paul \& Michael Pryke (red.) (2002):

Cultural Economy: Cultural Analysis and Commercial Life, London, Sage.

Gill, Rosalind \& Andy Pratt (2008): In the Social Factory? Immaterial Labour, Precariousness and Cultural Work, i Theory, Culture \& Society, 25, 7-8, 1-30.

Gomart, Emilie (2004): Surprised by Methadone: in Praise of Drug Substitution Treatment in a French Clinic, i Body \& Society, 10, 2-3, 85-110.

Gomart, Emilie \& Antoine Hennion (1999): A sociology of attachment: music amateurs, drug users, i John Law \& John Hassard (red.): Actor Network Theory and After, Oxford, Blackwell Publishers, 220-247.

Grint, Keith \& Steve Woolgar (1997): The Machine at Work: Technology, Work, and Organization, Cambridge, Polity Press.

Hardt, Michael (1999): Affective Labor, i Boundary 2, 26, 2, 89-100.

Hardt, Michael \& Antonio Negri (2000): Empire, Cambridge, Harvard University Press.

Hardt, Michael \& Antonio Negri (2004): Multitude: War and Democracy in the Age of Empire. New York: Penguin

Hennion, Antoine (2001): Music Lovers: Taste as Performance, i Theory, Culture \& Society, $18,5,1-22$.

Hennion, Antoine (2007): Those Things That Hold Us Together: Taste and Sociology, i Cultural Sociology, 1, 1, 97-114.

Hesmondhalgh, David \& Sarah Baker (2008): Creative Work and Emotional Labour in the Television Industry, i Theory, Culture \& Society, 25, 7-8, 97-118.

Hochschild, Arlie R. (1983): The Managed Heart: Commercialization of Human Feeling, Berkeley, University of California Press.

Jantzen, Christian \& Tove Arendt Rasmussen (2006): Oplevelsesøkonomi: Vinkler på forbrug, Aalborg, Aalborg Universitetsforlag.

Jensen, Casper Bruun (2010): Ontologies for Developing Things: Making Health Care Fu- tures Through Technology, Rotterdam, Sense Publishers.

Jespersen, Astrid Pernille (2007): Engagement $i$ arbejdet?: Konsultationsprocesser hos danske praktiserende loeger. Ph.d.-afhandling, Københavns Universitet.

Juul Nielsen, Annegrete (2010): Traveling Technologies and Transformations in Health Care, Frederiksberg, Samfundslitteratur, Ph.D. Serie; 36.2010.

Langstrup, Henriette (2005): Linking Healthcare: An Inquiry into the Changing Performances of Web-based Technology for Asthma Monitoring, København, Samfundslitteratur, Ph.D Serie; 2005-32.

Latour, Bruno (2004): How to Talk About the Body? The Normative Dimension of Science Studies, i Body \& Society, 10, 2-3, 205-229.

Mauss, Marcel (2001): A General Theory of Magic, London, Routledge.

McRobbie, Angela (2002): From Holloway to Hollywood: Happiness at Work in the New Cultural Economy, i Paul du Gay \& Michael Pryke (red.): Cultural Economy: Cultural Analysis and Commercial Life, London, Sage, 97-115.

Miller, Daniel (red.) (1998): Material Culture: Why Some Things Matter, Chicago, University of Chicago Press.

O'Dell, Tom (2005a): Meditation, Magic, and Spiritual Regeneration: Spas and the Mass Production of Serenity, i Orvar Löfgren \& Robert Willim (red.): Magic, Culture, and the New Economy, Oxford, Berg, 19-36.

O’Dell, Tom (2005b): Experiencescapes: Blurring Borders and Testing Connections, i Tom O’Dell \& Peter Billing (red.): Experiencescapes: Tourism, Culture and Economy, Frederiksberg, Samfundslitteratur, 11-34.

O’Dell, Tom (2005c): Spa-anläggningar, deras tjänster och den kulturella kontexten, i Hervé Corvellec \& Hans Lindquist (red.): Servicemötet: Multidisciplinära öppningar, Malmö, Liber, 64-80.

O'Dell, Tom (2007): Hospitality, Kinesthesis, and Health: Swedish Spas and the Market for Well-Being, i Jennie Germann Molz \& Sarah Gibson (red.): Mobilizing Hospitality: The Ethics of Social Relations in a Mobile 
World, London, Ashgate, 103-120.

O'Dell, Tom (2010): Spas: The Cultural Economy of Hospitality, Magic and the Senses, Lund, Nordic Academic Press.

Orlikowski, Wanda J. (2005): Material Works:

Exploring the Situated Entanglement of Technological Performativity and Human Agency, i Scandinavian Journal of Information Systems, 17, 1, 183-186.

Orlikowski, Wanda J. (2007): Sociomaterial Practices: Exploring Technology at Work, i Organization Studies, 28, 9, 1435-1448.

Pine, Joseph B. and James H. Gilmore (1999):

The Experience Economy, Boston, Harvard Business School Press.

Pratt, AC (2002): Hot Jobs in Cool Places. The Material Cultures of New Media Product Spaces: The Case of South of the Market, San Francisco, Information, Communication \& Society, 5, 1, 27-50.
Sennett, Richard (1998): The Corrosion of Character: The Personal Consequences of Work in the New Capitalism, New York, Norton \& Co. Suchman, Lucy (1987): Plans and Situated Actions: The Problem of Human-machine Communication, New York, Cambridge University Press.

Vikkelsø, Signe (2005): Subtle Redistribution of Work, Attention and Risks: Electronic Patient Records and Organisational Consequences, Scandinavian Journal of Information Systems, 17, 1, 3-30.

Woolgar, Steve and Geoff Cooper (1999): Do Artefacts Have Ambivalence? Moses' Bridges, Winner's Bridges and Other Urban Legends in S\&TS, i Social Studies of Science, 29, 3, 433-449.

WTW (Wellness Tourism Worldwide) (2011): 4WR: Wellness: for Whom, Where, and What? Research Report, Xellum Ltd. (Hungary).

Annegrete Juul Nielsen, ph.d., er adjunkt på Institut for Folkesundhedsvidenskab, Københavns Universitet

e-mail: anjn@sund.ku.dk

Sara Malou Strandvad, ph.d., er lektor på Performance-design, Institut for Kommunikation, Virksomhed og Informationsteknologier, Roskilde Universitet

e-mail:malou@ruc.dk 